\title{
Effectiveness of surgical revascularization for stroke prevention in pediatric patients with sickle cell disease and moyamoya syndrome
}

\author{
Wuyang Yang, MD, ${ }^{1}$ Risheng Xu, MD, PhD, ${ }^{1}$ Jose L. Porras, BS, ${ }^{1}$ Clifford M. Takemoto, MD, ${ }^{2}$ \\ Syed Khalid, BS, ${ }^{1}$ Tomas Garzon-Muvdi, MD, ${ }^{1}$ Justin M. Caplan, MD, ${ }^{1}$ Geoffrey P. Colby, MD, PhD, ${ }^{1}$ \\ Alexander L. Coon, MD, ${ }^{1}$ Rafael J. Tamargo, MD, ${ }^{1}$ Judy Huang, MD, ${ }^{1}$ and Edward S. Ahn, MD ${ }^{1}$ \\ 1'Department of Neurosurgery and 2Division of Pediatric Hematology, Johns Hopkins University School of Medicine, \\ Baltimore, Maryland
}

OBJECTIVE Sickle cell disease (SCD) in combination with moyamoya syndrome (MMS) represents a rare complication of SCD, with potentially devastating neurological outcomes. The effectiveness of surgical revascularization in this patient population is currently unclear. The authors' aim was to determine the effectiveness of surgical intervention in their series of SCD-MMS patients by comparing stroke recurrence in those undergoing revascularization and those undergoing conservative transfusion therapy.

METHODS The authors performed a retrospective chart review of patients with MMS who were seen at the Johns Hopkins Medical Institution between 1990 and 2013. Pediatric patients (age < 18 years) with confirmed diagnoses of SCD and MMS were included. Intracranial stroke occurrence during the follow-up period was compared between surgically and conservatively managed patients.

RESULTS A total of 15 pediatric SCD-MMS patients (28 affected hemispheres) were included in this study, and all were African American. Seven patients (12 hemispheres) were treated with indirect surgical revascularization. The average age at MMS diagnosis was $9.0 \pm 4.0$ years, and 9 patients $(60.0 \%)$ were female. Fourteen patients (93.3\%) had strokes before diagnosis of MMS, with an average age at first stroke of $6.6 \pm 3.9$ years. During an average follow-up period of 11.6 years, 4 patients in the conservative treatment group experienced strokes in 5 hemispheres, whereas no patient undergoing the revascularization procedure had any strokes at follow-up $(p=0.029)$. Three patients experienced immediate postoperative transient ischemic attacks, but all recovered without subsequent strokes.

CONCLUSIONS Indirect revascularization is suggested as a safe and effective alternative to the best medical therapy alone in patients with SCD-MMS. High-risk patients managed on a regimen of chronic transfusion should be considered for indirect revascularization to maximize the effect of stroke prevention.

https://thejns.org/doi/abs/10.3171/2017.1.PEDS16576

KEY WORDS sickle cell disease; moyamoya syndrome; pediatric; revascularization; vascular disorders

$\mathrm{I}$ SCHEMIC stroke is a prevalent and devastating complication in patients with sickle cell disease (SCD) caused by a vaso-occlusive phenomenon, with most patients having symptomatic onset in childnhood. The incidence rate of an initial stroke is reported to be $0.76 \%$ per year, translating to a $13.7 \%$ cumulative risk of stroke by 18 years of age ${ }^{15}$ Compared with the general pediatric population, the stroke risk in patients with SCD is approximately 330 times higher. ${ }^{8}$ Within the SCD patient population, moyamoya syndrome (MMS) has been reported to be found in $43 \%$ of patients. 7 The combination of SCD and MMS (SCD-MMS) confers a much higher risk of ischemic stroke, with SCD-MMS patients having twice the risk of experiencing recurrent cerebrovascular events and a 5

ABBREVIATIONS DSA = digital subtraction angiography; EDAMS = encephalo-duro-arterio-myo-synangiosis; EDAS = encephalo-duro-arterio-synangiosis; MMS = moyamoya syndrome; $S C D=$ sickle cell disease.

SUBMITTED October 7, 2016. ACCEPTED January 19, 2017.

INCLUDE WHEN CITING Published online July 7, 2017; DOI: 10.3171/2017.1.PEDS16576. 
times higher likelihood of having 2 recurrent cerebrovascular events compared with patients with SCD only. ${ }^{8}$

The standard of care for lowering stroke risk in SCD patients entails chronic blood transfusions with a target fraction of hemoglobin S less than 30\%.,14,16,20 However, for patients with combined SCD-MMS, the efficacy of transfusion therapy is limited, and the role of revascularization surgery is not well delineated. Recent studies have reported on the use of surgical revascularization in SCDMMS patients and have suggested a posttreatment risk reduction of recurrent strokes when compared with the pretreatment risk. ${ }^{9-11,18}$ Despite promising results, the generalizability of these studies is limited by a lack of control groups comprising conservatively managed SCD-MMS patients. ${ }^{9}$ Without directly comparing surgical and medical management groups, the relative effectiveness and safety of surgical revascularization for lowering stroke risk in SCD-MMS patients remains unclear. The current study was therefore undertaken to compare the effectiveness of surgical versus medical management for preventing stroke in patients with SCD-MMS.

\section{Methods \\ Study Cohort}

We retrospectively reviewed our database of patients with a diagnosis of moyamoya disease or MMS who were seen in our institution between January 1990 and October 2015. This study was approved by our institutional review board. The diagnosis of MMS was determined by direct digital subtraction angiography (DSA) readings or documentation depicting internal carotid artery terminal stenosis with the presence of moyamoya collateral vessels. Data regarding pediatric patients ( $<18$ years) with a confirmed diagnosis of SCD were retrieved from the database. Both surgically treated and conservatively managed patients were included in this study. Patients with incomplete baseline data and those lost to follow-up were excluded from our study.

\section{Definition of Variables, Treatment, and Outcomes}

Demographic, clinical, and angiographic data were retrieved from electronic patient records. Patient age was defined as the age at time of MMS diagnosis. Baseline stroke included both silent strokes and symptomatic strokes before the diagnosis of MMS. Two management groups were defined: conservative and surgical. Patients who underwent initial conservative management over 5 years but crossed over to the surgical group due to progressive worsening of symptoms or strokes were still included the conservative management group, since the revascularization procedure was considered as a salvage management strategy. The follow-up period was defined as the interval between the first surgical treatment and last follow-up for surgically managed patients, or the interval between MMS diagnosis and last follow-up for conservatively treated patients. Our primary outcome measure was stroke recurrence.

All patients who underwent surgery underwent indirect revascularization by encephalo-duro-arterio-synangiosis (EDAS, $\mathrm{n}=3$ ), encephalo-duro-arterio-myo-synangiosis (EDAMS, $n=1)$, or pial synangiosis $(n=4)$. The main dif-

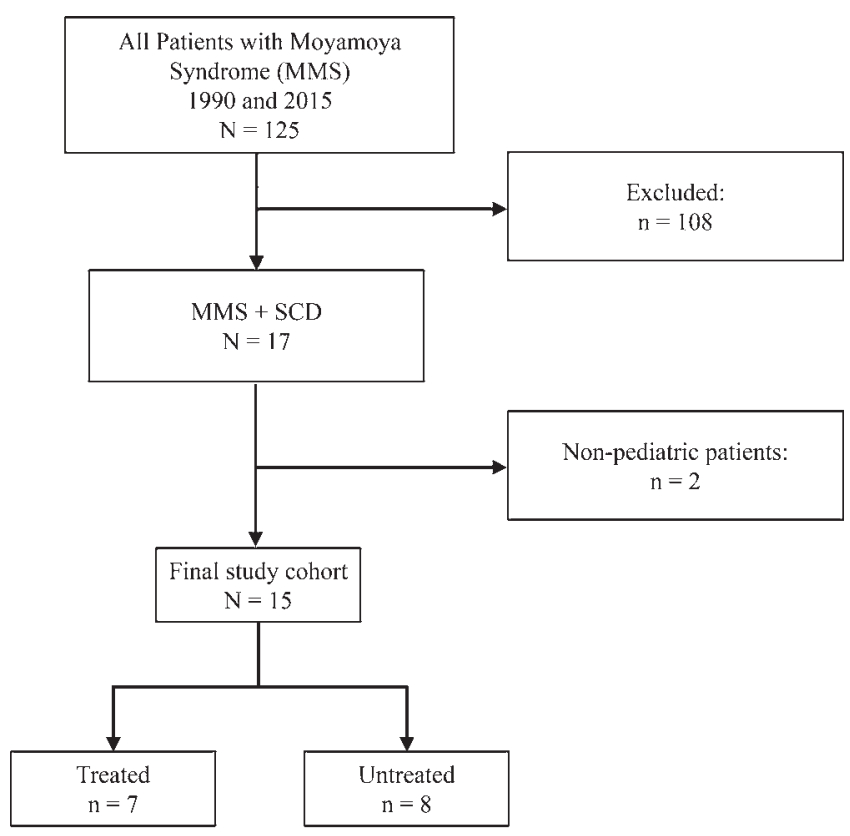

FIG. 1. Flow diagram showing patient cohort selection in our study.

ference with the pial synangiosis procedure was opening of the arachnoid layer and suturing the superficial temporal artery to the pial surface in accordance with previously reported series. ${ }^{3,10}$ Five patients underwent bilateral revascularization procedures, and 4 of these patients underwent bilateral craniotomies on the same day during 1 anesthesia session.

\section{Data Analysis}

Baseline characteristics and follow-up stroke occurrence were compared between surgically treated and conservatively treated patients. The Student t-test was used for continuous variables, and the chi-square test was used for categorical variables. The incidence rate of recurrent strokes after surgical intervention or conservative management was represented as cases per 100 patient-years and was determined by dividing the total number of strokes at follow-up by the total follow-up period. Statistical significance was defined as $p<0.05$, and all statistical analyses were performed using $\mathrm{R}$ statistical software (version 3.1.1, 2013).

\section{Results}

\section{Patient Population and Baseline Characteristics}

A total of 15 pediatric patients with SCD-MMS met our inclusion criteria. Detailed illustration of the patient selection process at each step is depicted in a flow diagram (Fig. 1). Further characterization of each patient is listed in Table 1, and an illustrative case is shown in Fig. 2. Among these patients, 7 patients were initially managed surgically, and 8 patients were managed conservatively. One patient in the conservative group crossed over to the surgical group because of recurrent bilateral stroke after 6 years of chronic transfusion therapy. The average age at moyamoya diagnosis was $9.0 \pm 4.0$ years. Nine patients $(60.0 \%)$ 
TABLE 1. Characteristics of all 15 patients with SCD-MMS

\begin{tabular}{|c|c|c|c|c|c|c|c|c|c|c|c|c|c|c|c|}
\hline \multirow[b]{3}{*}{$\begin{array}{c}\text { Case } \\
\text { No. }\end{array}$} & \multicolumn{9}{|c|}{ Baseline Characteristics* $^{*}$} & \multicolumn{2}{|c|}{ Treatment } & \multicolumn{4}{|c|}{ Follow-Up } \\
\hline & \multirow{2}{*}{$\begin{array}{c}\text { Age } \\
\text { (yrs), } \\
\text { Sex }\end{array}$} & \multirow[b]{2}{*}{ Sxs } & \multirow[b]{2}{*}{ Transfusion } & \multicolumn{3}{|c|}{ Baseline Stroke } & \multicolumn{3}{|c|}{ Lab Values $\ddagger$} & \multirow[b]{2}{*}{ Type } & \multirow[b]{2}{*}{$\begin{array}{c}\text { Treatment } \\
\text { Detail }\end{array}$} & \multirow[b]{2}{*}{ Yrs } & \multicolumn{2}{|c|}{ Stroke } & \multirow[b]{2}{*}{$\begin{array}{c}\text { Social } \\
\text { Function** }\end{array}$} \\
\hline & & & & $\begin{array}{c}\text { Onset } \\
\text { Age (yrs) }\end{array}$ & $\begin{array}{c}\text { Side of } \\
\text { 1st Stroke }\end{array}$ & $\begin{array}{l}\text { Silent } \\
\text { Stroke }\end{array}$ & $\mathrm{Hgb}$ & $\begin{array}{l}\mathrm{Hgb} \\
\mathrm{S}(\%)\end{array}$ & Ferritin & & & & $\begin{array}{l}\text { Interval } \\
\text { in Yrs }\end{array}$ & Side & \\
\hline 1 & $16, F$ & W/HA/C & + & 7 & Lt & Bilat & 10.3 & 25.5 & 822 & Cons & NA & 8.6 & NA & NA & Unemployed \\
\hline 2 & $7, \mathrm{~F}$ & FD & + & 7 & Lt & Lt & 8.8 & 5.4 & 1396 & Cons & NA & 9.7 & NA & NA & School \\
\hline 3 & $14, \mathrm{~F}$ & W & + & 14 & $\mathrm{Lt}$ & Bilat & 10.3 & 11.40 & 6879 & Cons & NA & 12.6 & 5.8 & Lt & Unemployed \\
\hline 4 & $2, \mathrm{~F}$ & W & + & 2 & $\mathrm{Lt}$ & NA & Unk & Unk & Unk & Cons & NA & 33.8 & 26.9 & Rt & Unemployed \\
\hline 5 & $6, F$ & NA & + & 6 & $\mathrm{Lt}$ & Bilat & 9.1 & 29.2 & 450 & Cons & NA & 8.6 & 1.7 & $\mathrm{Rt}$ & School \\
\hline 6 & $9, F$ & W/Sp & + & 3 & $\mathrm{Lt}$ & NA & 9.4 & 25.1 & 1927 & Cons & NA/PS§ & 15 & 5.6 & Bilat & School \\
\hline 7 & $9, M$ & NA & + & NA & NA & Rt & 7.0 & 55.8 & 3373 & Cons & NA & 5.7 & NA & NA & School \\
\hline 8 & $14, M$ & W/Sp & + & 5 & $\mathrm{Lt}$ & NA & 9.4 & 13.1 & 2203 & Cons & NA & 13.5 & NA & NA & Unemployed \\
\hline 9 & $8, F$ & $\begin{array}{c}\text { W/Sp/ } \\
\text { Sz }\end{array}$ & + & 8 & $\mathrm{Rt}$ & NA & 10.1 & 9.6 & Unk & Int & Rt EDAMS & 7.2 & NA & NA & School \\
\hline 10 & $8, F$ & $\mathrm{HA}$ & $+/-\dagger$ & 12 & $\mathrm{Lt}$ & NA & Unk & Unk & Unk & Int & $\begin{array}{l}\text { Bilat } \\
\text { EDAS }\end{array}$ & 7.4 & NA & NA & Schoolt† \\
\hline 11 & $6, \mathrm{~F}$ & $\begin{array}{l}\text { W/HAl } \\
\mathrm{Sp}\end{array}$ & + & 4 & Lt & Bilat & 8.5 & 19.0 & 241 & Int & Rt PS & 10.4 & NA & NA & School \\
\hline 12 & $13, M$ & W/Sz & + & 2 & Rt & NA & 9.2 & 9.3 & 3192 & Int & $\begin{array}{r}\text { Bilat PS + } \\
\text { EDASף }\end{array}$ & 2 & NA & NA & Schoolłf \\
\hline 13 & $8, M$ & W & + & 8 & $\mathrm{Rt}$ & NA & 10.5 & 51.0 & 1570 & Int & Bilat PS & 6 & NA & NA & School \\
\hline 14 & $2, M$ & W & + & 2 & $\mathrm{Rt}$ & NA & Unk & Unk & Unk & Int & $\begin{array}{l}\text { Bilat } \\
\text { EDAS }\end{array}$ & 14.8 & NA & NA & Unemployed \\
\hline 15 & $13, M$ & W/Sp & + & 12 & Bilat & Rt & 10.8 & 82.5 & 713 & Int & Bilat PS & 19.1 & NA & NA & School \\
\hline
\end{tabular}

Cons = conservative; FD = facial droop/weakness; $\mathrm{HA}=$ headache; $\mathrm{Hgb}=$ hemoglobin; Hgb S = hemoglobin S; int = intervention; $\mathrm{NA}=$ not applicable; $\mathrm{PS}=$ pial synangiosis; Sp = speech disturbance; Sxs = symptoms; Sz = seizures; unk = unknown; $\mathrm{W}=$ weakness; + = yes.

* Baseline characteristics were defined as parameters at the time of diagnosis of MMS.

$\dagger$ As needed (+/-) instead of chronic transfusion in Case 10.

$\ddagger$ Laboratory units: Hgb, g/dl; ferritin, $\mathrm{ng} / \mathrm{ml}$.

$\S$ The patient in Case 6 was initially conservatively managed but crossed over to pial synangiosis after 4 recurrent strokes 6 years after starting chronic transfusion.

I The patient in Case 12 underwent left PS and right EDAS.

** All unemployed patients had completed 12th grade education.

$\dagger \dagger$ School for the patient in Case 10 at last follow-up was temporarily interrupted due to the complaint of severe headaches. The patient is currently under evaluation for bone marrow transplant.

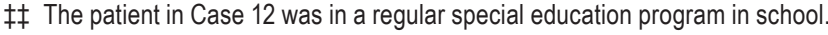

were female, and all patients were African American. The average age at first stroke was 6.6 years, with the majority being unilateral strokes $(n=13,86.7 \%)$. Only 1 patient was asymptomatic at presentation; this patient underwent carotid transcranial Doppler ultrasound screening that revealed increased blood flow velocity, leading to further angiographic workup and a subsequent diagnosis of MMS. All patients with right-sided and bilateral strokes were selected for a revascularization procedure $(\mathrm{p}=0.033)$. No significant differences between the 2 groups were found for other variables (Table 2).

\section{Chronic Transfusion, Revascularization, and Outcome}

A total of 14 patients $(93.3 \%)$ were managed by chronic transfusion, with the majority being on a monthly transfusion regimen $(n=10)$. Only 1 patient received transfusions as needed due to mild symptoms and noncompliance of the patient for chronic transfusion. All patients experienced different degrees of iron overload, with average ferritin levels at $2070.0 \pm 1902.5 \mathrm{ng} / \mathrm{ml}$. While the conservative group had a higher ferritin level compared with the surgical group, the difference was not statistically significant $(p=0.363)$. The average hemoglobin level was approximately $9.5 \mathrm{~g} / \mathrm{dl}$, and average percentage of hemoglobin $\mathrm{S}$ was $22.4 \%$, with no differences between the treatment groups. All revascularization procedures were performed via indirect anastomosis. Among patients who underwent revascularization, 2 patients were treated only on the right side, and the other 5 patients were treated bilaterally. Of the 2 patients with unilateral revascularization, one patient (Case 9) presented with right-sided stroke only and therefore underwent revascularization on the right side. The other patient (Case 11) presented with an episode of bilateral ischemic attack; MRI demonstrated nonacute infarctions bilaterally and DSA revealed moyamoya-like vessel changes on the right side. Therefore, provided with no acute left-sided strokes and appearance of right-sided MMS, a decision was made to only perform a right-sided pial synangiosis. Of note, 3 patients (42.8\%) experienced transient ischemic attacks (TIAs) during the immediate postoperative period in the hospital, but all patients recov- 

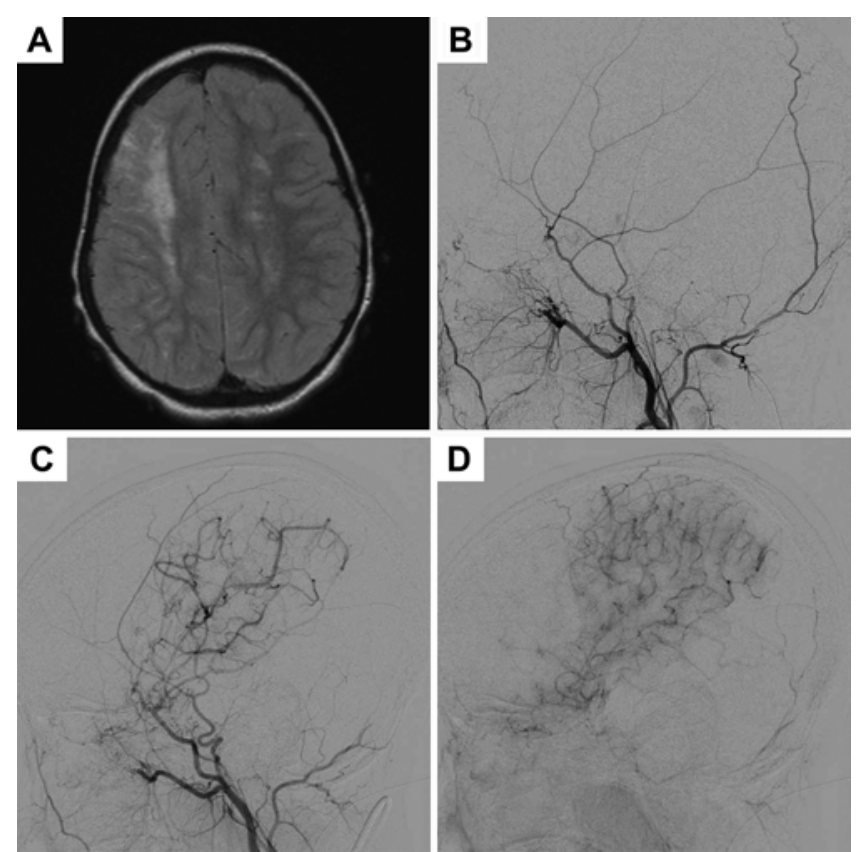

FIG. 2. Case 11. A 6-year-old girl with history of sickle cell disease presented with headaches, mild slurred speech, and left-sided weakness. The patient's medical history was significant for a left-sided stroke, followed by a bilateral stroke at the age of 4 years, which left the patient with subtle residual weakness and occasional headaches. She was managed on a chronic monthly transfusion regimen after her second stroke. T2-weighted FLAIR MRI showed bilateral periventricular hyperintense signals that were more pronounced on the right. The patient was evaluated for surgical management due to concern of growth of hyperintensities on follow-up MRI (A) and underwent uncomplicated right-sided pial synangiosis. DS angiograms of the right external carotid artery preoperatively (B) and 2 years postoperatively in the early (C) and late (D) arterial phases reveal improved revascularization of the posterior twothirds of the right middle cerebral artery territory. On last follow-up at the age of 10 years, the patient has been actively maintained on a regimen of regular transfusion therapy and has not suffered additional episodes of strokes since surgery.

ered to baseline without subsequent major stroke events. These TIAs were marked by recurrent weakness, speech disturbance, or gait instability and occurred between the perioperative period and 1 month after surgery. One patient in the conservative group crossed over to the treatment group because of recurrent bilateral strokes 6 years after MMS diagnosis, and no strokes occurred after the revascularization procedure.

During an average follow-up period of 11.6 years (174.6 patient-years), 4 patients experienced recurrent stroke, translating to a general risk of 2.3 events per 100 patientyears $(2.3 \%$ per year) in this population. All 4 patients with recurrent stroke had been managed conservatively, rendering an annual risk of stroke of $4.2 \%$ in the conservative group and $0.0 \%$ in the intervention group. The control of recurrent strokes was superior in the surgical group compared with the conservative group $(\mathrm{p}=0.029)$. Kaplan-Meier survival analysis of stroke-free survival comparing conservative management and surgical intervention is shown in Fig. 3; the log-rank test did not show significance $(p=0.200)$ between the 2 modalities despite distinct visual separation of the curves. As shown in Table
1, all patients were able to continue education at school or complete 12th grade education. One patient (Case 10) experienced severe headaches at baseline; the revascularization procedure did not improve her symptoms, and her education was temporarily interrupted at last follow-up to undergo evaluation for bone marrow transplant. Of those older than 18 years at last follow-up $(n=7), 5$ patients were unemployed, and 2 patients (one conservatively managed and the other treated with bilateral pial synangiosis) were able to continue higher education in college with minimal complaints.

\section{Discussion \\ Higher Risk of Stroke in SCD-MMS Patients}

This retrospective cohort study examined the safety and effectiveness of surgical revascularization for select SCD-MMS patients. To our knowledge, this study represents one of the first to directly compare the risk of recurrent strokes between conservatively and surgically managed groups in this population. The majority of patients (93.3\%) experienced at least one symptomatic stroke prior to presentation, and many $(46.7 \%)$ were found to have silent infarctions on further workup after presentation. Despite a known risk of stroke in the general SCD population at approximately $10 \%, 1,2,7,19$ the risk of stroke in SCD-MMS patients is significantly higher. In a review of 30 patients with SCD-MMS by Kennedy et al., the proportion of patients with ischemic strokes has been noted to be $77.0 \%$ (range $71.0 \%-100.0 \%$ ). ${ }^{11}$ In concordance with this result, a more recent study by Griessenauer et al. examined 48 SCD patients who were on a regimen of chronic transfusion. ${ }^{9}$ The authors identified 14 patients with combined MMS, of whom $71.4 \%$ presented with stroke. In our experience, 14 of 15 patients (93\%) experienced a symptomatic stroke prior to diagnosis, confirming the high risk of strokes in this select population.

In addition to more frequent stroke presentations, SCDMMS patients also appeared to be at significant risk of recurrent strokes compared with patients with SCD only. Dobson et al. first reported moyamoya collaterals as a significant predictor of subsequent strokes in SCD patients after being placed on a regimen of chronic transfusion therapy. In their cohort of 19 SCD patients with angiographically confirmed moyamoya-like collaterals, the average age at first stroke was 7.8 years, and 11 patients (58\%) experienced recurrent strokes after the first stroke during a follow-up period of 8.1 years. This result is quite similar to our study's findings, which demonstrated a recurrent stroke risk of $50.0 \%$ in the conservative treatment group.

\section{Conservative Versus Surgical Intervention for SCD-MMS Patients}

Chronic blood transfusions are considered standard and effective primary treatment to prevent recurrent stroke in patients with SCD, whereas for secondary stroke prevention it is also recommended..$^{13,23}$ Hydroxyurea may be an alternative for secondary stroke prevention, but may be less effective than transfusions. ${ }^{22}$ The utility of blood transfusions in primary stroke prevention in SCD patients 
TABLE 2. Comparison of characteristics between conservatively and surgically treated patients with SCD-MMS

\begin{tabular}{|c|c|c|c|c|}
\hline Parameter & Total $(n=15)$ & Conservative $(n=8)$ & Surgical $(n=7)$ & p Value \\
\hline Sex, n (\%) & & & & 0.205 \\
\hline $\mathrm{F}$ & $9(60.0)$ & $6(75.0)$ & $3(42.9)$ & \\
\hline M & $6(40.0)$ & $2(25.0)$ & $4(57.1)$ & \\
\hline \multicolumn{5}{|l|}{ Race, $n(\%)$} \\
\hline African American & $15(100.0)$ & $8(100.0)$ & $7(100.0)$ & \\
\hline Age at diagnosis in yrs, mean (SD) & $9.0(4.0)$ & $9.5(4.5)$ & $8.4(3.3)$ & 0.613 \\
\hline MMS laterality, $\mathrm{n}(\%)$ & & & & 0.919 \\
\hline Lt side only & $2(13.3)$ & $1(12.5)$ & $1(14.3)$ & \\
\hline Bilat & $13(86.7)$ & $7(87.5)$ & $6(85.7)$ & \\
\hline Chronic transfusion, $\mathrm{n}(\%)$ & & & & 0.268 \\
\hline No & $1(6.7)$ & $0(0.0)$ & $1(14.3)$ & \\
\hline Yes & $14(93.3)$ & $8(100.0)$ & $6(85.7)$ & \\
\hline $\mathrm{Hgb}$ at diagnosis in $\mathrm{g} / \mathrm{dl}$, mean (SD)* & $9.5(1.1)$ & $9.2(1.1)$ & $9.8(1.1)$ & 0.317 \\
\hline $\mathrm{Hgb} \mathrm{S}$ at diagnosis in $\%$, mean $(\mathrm{SD})^{*}$ & $22.4(16.3)$ & $24.0(17.0)$ & $21.0(17.0)$ & 0.766 \\
\hline Ferritin level at diagnosis in ng/ml, mean (SD)† & $2070.0(1902.5)$ & $2435.7(2181.8)$ & $1429.0(1297.7)$ & 0.363 \\
\hline Age at 1 st stroke in yrs, mean $(S D) \ddagger$ & $6.6(3.9)$ & $6.2(3.9)$ & $7.0(4.2)$ & 0.710 \\
\hline 1st stroke laterality, n (\%) & & & & $0.033 \S$ \\
\hline Lt side only & $9(60.0)$ & $7(87.5)$ & $2(28.6)$ & \\
\hline Rt side only & $4(26.7)$ & $0(0.0)$ & $4(57.1)$ & \\
\hline Bilat & $1(6.7)$ & $0(0.0)$ & $1(14.3)$ & \\
\hline No stroke & $0(0.0)$ & $1(12.5)$ & $0(0.0)$ & \\
\hline \multicolumn{5}{|l|}{ Op treatment laterality, $\mathrm{n}(\%)$} \\
\hline Rt side only & & & $2(28.6)$ & \\
\hline Bilat & & & $5(71.4)$ & \\
\hline Follow-up duration in yrs, mean (SD) & $11.6(7.3)$ & $13.5(8.2)$ & $9.6(5.3)$ & 0.325 \\
\hline Follow-up stroke, $\mathrm{n}(\%)$ & & & & $0.029 \S$ \\
\hline No & $11(73.3)$ & $4(50.0)$ & $7(100.0)$ & \\
\hline Yes & $4(26.7)$ & $4(50.0)$ & $0(0.0)$ & \\
\hline $\begin{array}{l}\text { * } n=12 . \\
n=11 . \\
\text { † }=14 . \\
\S \text { Statistically significant }(p<0.05) \text {. }\end{array}$ & & & & \\
\hline
\end{tabular}

with elevated transcranial Doppler ultrasound velocities has been unequivocally established through landmark studies such as the STOP (Stroke Prevention in Sickle Cell Anemia) trial, which showed a $92 \%$ risk reduction of stroke in the intervention arm. ${ }^{2}$ Subsequently, Adams and Brambilla conducted the STOP 2 trial, which confirmed the adverse effects of discontinuing blood transfusion at 30 months, demonstrating the efficacy of life-long transfusion therapy for stroke prevention in SCD patients. ${ }^{1}$ Separately, DeBaun et al. suggested in the SIT (Silent Cerebral Infarct Multi-Center Clinical Trial) study that patients with existing silent cerebral infarctions undergoing routine blood transfusions were half as likely to experience stroke progression compared with those managed by observation only. ${ }^{4}$ However, chronic transfusions may expose patients to significant iron overload, which can lead to alloimmunization. ${ }^{5,6,12}$ Indeed, our study corroborates the concern for iron overload, as the average ferritin level in our patients exceeded $2000 \mathrm{ng} / \mathrm{ml}$. The ongoing TWiTCH (TCD With Transfusions Changing to Hydroxyurea) trial was initiated to evaluate hydroxyurea as an alternative to chronic transfusion in pediatric patients who have undergone at least 1 year of transfusion therapy; recently published Phase III trial results were promising regarding the stroke prevention effect of hydroxycarbamide. ${ }^{21}$

Contrary to the high-quality evidence for stroke prevention in pediatric patients with SCD only, there is currently no Level I/II evidence available for SCD-MMS patients, which is largely attributable to the scarcity of this devastating combination. Conservative management for this particular cohort appears suboptimal; ${ }^{7}$ conversely, in procedure-oriented series, stroke prevention is suggested to be optimal for patients undergoing indirect revascularization procedures.9-11,17,18 Nevertheless, without solid evidence confirming the effectiveness of surgical revascularization in this rare disease combination, the decision-making process for best prognosis is challenging. At our institution, conservative management is the primary modality of management, and surgical intervention is reserved for patients with deteriorating clinical condition under con- 


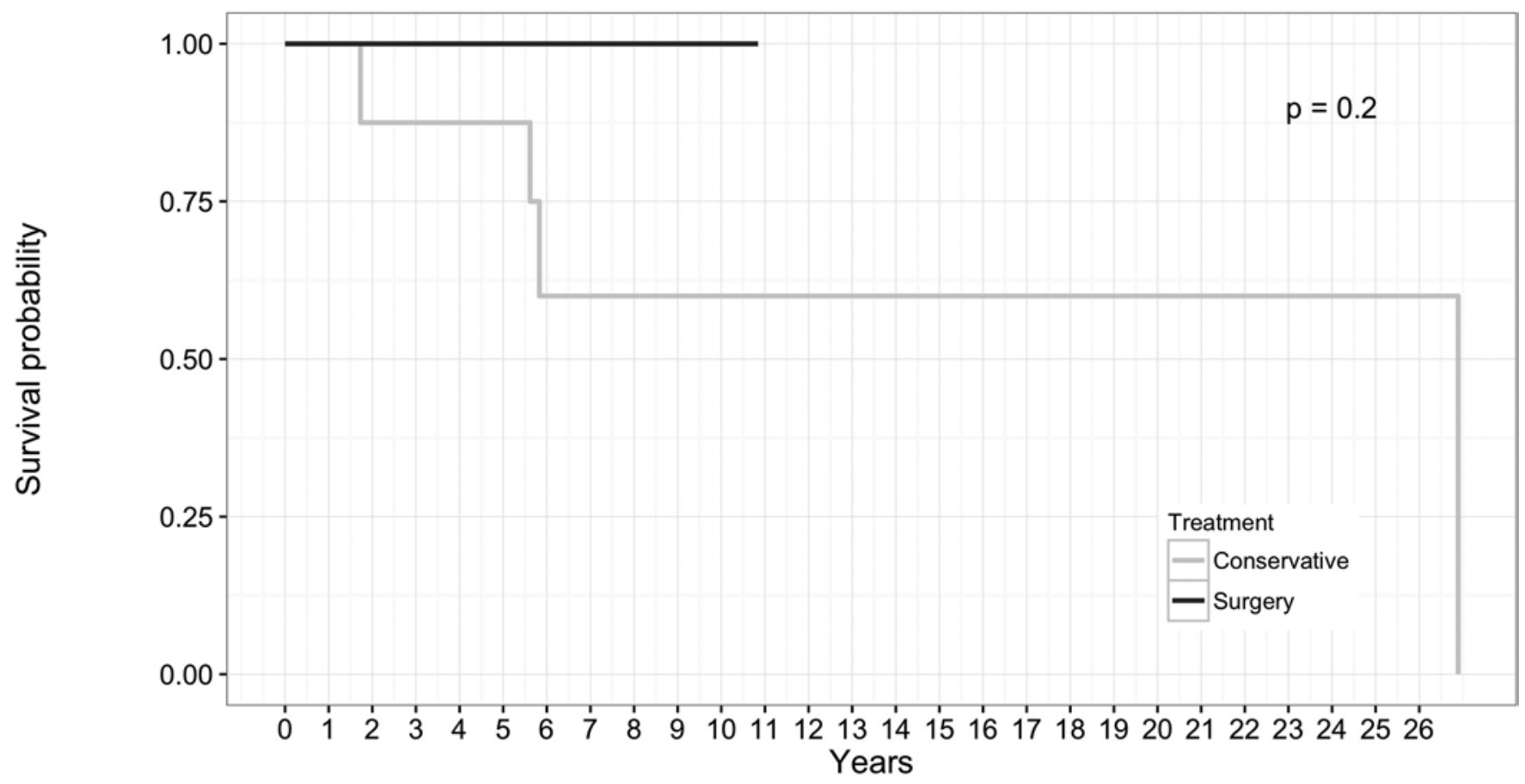

Number at risk by time

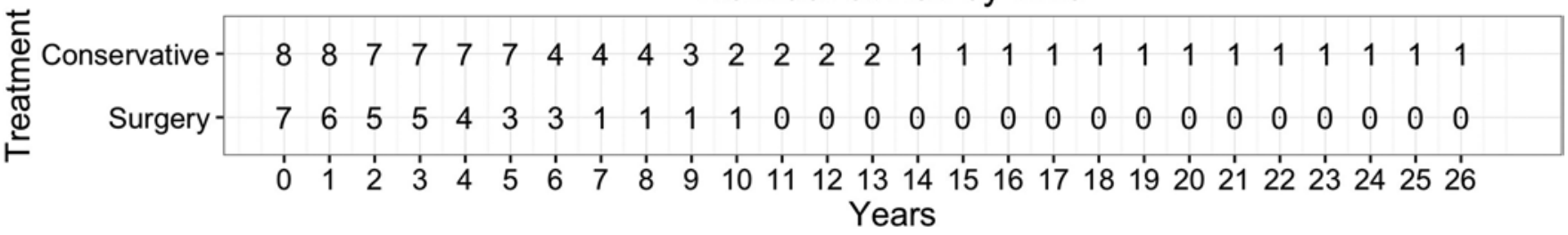

FIG. 3. Kaplan-Meier stroke-free survival curve between surgical revascularization and conservative management.

servative management. However, individualized selection of treatment based on physician experience is common, given the lack of evidence. Our study, which is one of the first to directly compare both conservatively and surgically managed patients at a single center, demonstrates the effectiveness of revascularization in the prevention of recurrent strokes in the pediatric SCD-MMS population over conservative medical management. It is important to note, however, that despite surgical intervention, all patients in the revascularization cohort were maintained on a regimen of blood transfusions to continue the protective effect of conservative treatment. In other surgical cases, reduced or discontinued transfusion therapy has been described by Smith et al. ${ }^{18}$ Based on previously reported results with surgery and findings from our study, it seems reasonable to study the reduction in transfusion frequency after surgical revascularization to decrease iron levels.

\section{Study Limitations}

One of the major concerns in this study is the associated selection bias in which patients with higher risk of stroke were selected for surgical intervention. However, this bias was in favor of our conclusion in that, despite considered higher risk for stroke, none of the patients in the surgical group experienced further stroke after intervention. Given the rare nature of this disease combination, our case se- ries is limited by sample size. Regardless, the statistical significance of our findings suggests that surgical revascularization is effective in reducing recurrent stroke risk in SCD-MMS patients. As SCD is a lifelong disease, an incomplete observation bias may exist if follow-up times are limited. However, our average follow-up period of 11.6 years represents an interval almost twice the median interval to recurrent strokes in our study (5.7 years), implying that most likely we were able to successfully detect our primary end point.

\section{Conclusions}

To the best of our knowledge, our study represents the first attempt to directly compare conservative management with surgical revascularization in patients with SCD-MMS. Despite a limited sample size, our results indicate a potential benefit in stroke prevention with surgical revascularization. Our results are in accordance with those of recent reports of a high risk of stroke in conservatively managed SCD-MMS patients. Moreover, we show a potential reduction in recurrent stroke for patients who underwent surgical revascularization. For patients with deteriorating clinical conditions under conservative management, we believe that surgical intervention may maximize the effect for stroke prevention. Further prospective stud- 
ies are warranted to delineate this potential benefit in this select group of highly challenging patients.

\section{References}

1. Adams RJ, Brambilla D: Discontinuing prophylactic transfusions used to prevent stroke in sickle cell disease. N Engl J Med 353:2769-2778, 2005

2. Adams RJ, McKie VC, Hsu L, Files B, Vichinsky E, Pegelow $\mathrm{C}$, et al: Prevention of a first stroke by transfusions in children with sickle cell anemia and abnormal results on transcranial Doppler ultrasonography. N Engl J Med 339:5-11, 1998

3. Adelson PD, Scott RM: Pial synangiosis for moyamoya syndrome in children. Pediatr Neurosurg 23:26-33, 1995

4. DeBaun MR, Gordon M, McKinstry RC, Noetzel MJ, White DA, Sarnaik SA, et al: Controlled trial of transfusions for silent cerebral infarcts in sickle cell anemia. N Engl J Med 371:699-710, 2014

5. DeBaun MR, Kirkham FJ: Central nervous system complications and management in sickle cell disease: a review. Blood 127:829-838, 2016

6. DeBaun MR, Kirkham FJ: New option for primary stroke prevention in sickle cell anaemia. Lancet 387:626-627, 2016

7. Dobson SR, Holden KR, Nietert PJ, Cure JK, Laver JH, Disco D, et al: Moyamoya syndrome in childhood sickle cell disease: a predictive factor for recurrent cerebrovascular events. Blood 99:3144-3150, 2002

8. Fullerton HJ, Wu YW, Zhao S, Johnston SC: Risk of stroke in children: ethnic and gender disparities. Neurology 61:189194, 2003

9. Griessenauer CJ, Lebensburger JD, Chua MH, Fisher WS III, Hilliard L, Bemrich-Stolz CJ, et al: Encephaloduroarteriosynangiosis and encephalomyoarteriosynangiosis for treatment of moyamoya syndrome in pediatric patients with sickle cell disease. J Neurosurg Pediatr 16:64-73, 2015

10. Hankinson TC, Bohman LE, Heyer G, Licursi M, Ghatan S, Feldstein NA, et al: Surgical treatment of moyamoya syndrome in patients with sickle cell anemia: outcome following encephaloduroarteriosynangiosis. J Neurosurg Pediatr 1:211-216, 2008

11. Kennedy BC, McDowell MM, Yang PH, Wilson CM, Li S, Hankinson TC, et al: Pial synangiosis for moyamoya syndrome in children with sickle cell anemia: a comprehensive review of reported cases. Neurosurg Focus 36(1):E12, 2014

12. Lee MT, Piomelli S, Granger S, Miller ST, Harkness S, Brambilla DJ, et al: Stroke Prevention Trial in Sickle Cell Anemia (STOP): extended follow-up and final results. Blood 108:847-852, 2006

13. National Heart, Lung, and Blood Institute: Evidence-Based Management of Sickle Cell Disease. Expert Panel Report, 2014. Washington, DC: National Institutes of Health, 2014 (https://www.nhlbi.nih.gov/sites/www.nhlbi.nih.gov/files/ sickle-cell-disease-report\%20020816.pdf) [Accessed June 19, 2017]

14. Pegelow CH, Adams RJ, McKie V, Abboud M, Berman B, Miller ST, et al: Risk of recurrent stroke in patients with sickle cell disease treated with erythrocyte transfusions. J Pediatr 126:896-899, 1995

15. Powars D, Wilson B, Imbus C, Pegelow C, Allen J: The natural history of stroke in sickle cell disease. Am J Med 65:461-471, 1978
16. Russell MO, Goldberg HI, Hodson A, Kim HC, Halus J, Reivich M, et al: Effect of transfusion therapy on arteriographic abnormalities and on recurrence of stroke in sickle cell disease. Blood 63:162-169, 1984

17. Scott RM, Smith JL, Robertson RL, Madsen JR, Soriano SG, Rockoff MA: Long-term outcome in children with moyamoya syndrome after cranial revascularization by pial synangiosis. J Neurosurg 100 (2 Suppl Pediatrics):142-149, 2004

18. Smith ER, McClain CD, Heeney M, Scott RM: Pial synangiosis in patients with moyamoya syndrome and sickle cell anemia: perioperative management and surgical outcome. Neurosurg Focus 26(4):E10, 2009

19. Verduzco LA, Nathan DG: Sickle cell disease and stroke. Blood 114:5117-5125, 2009

20. Wang CJ, Kavanagh PL, Little AA, Holliman JB, Sprinz PG: Quality-of-care indicators for children with sickle cell disease. Pediatrics 128:484-493, 2011

21. Ware RE, Davis BR, Schultz WH, Brown RC, Aygun B, Sarnaik S, et al: Hydroxycarbamide versus chronic transfusion for maintenance of transcranial Doppler flow velocities in children with sickle cell anaemia-TCD With Transfusions Changing to Hydroxyurea (TWiTCH): a multicentre, openlabel, phase 3, non-inferiority trial. Lancet 387:661-670, 2016

22. Ware RE, Helms RW: Stroke With Transfusions Changing to Hydroxyurea (SWiTCH). Blood 119:3925-3932, 2012

23. Yawn BP, Buchanan GR, Afenyi-Annan AN, Ballas SK, Hassell KL, James AH, et al: Management of sickle cell disease: summary of the 2014 evidence-based report by expert panel members. JAMA 312:1033-1048, 2014

\section{Disclosures}

The authors report the following. Dr. Colby: received clinical/ research support for this study from Stryker and Medtronic. Dr. Coon: consultant for Medtronic, Stryker, and MicroVention.

\section{Author Contributions}

Conception and design: Ahn, Yang, Porras, Garzon-Muvdi, Huang. Acquisition of data: Yang, Porras. Analysis and interpretation of data: Yang, Takemoto. Drafting the article: Yang, Porras. Critically revising the article: Ahn, Yang, Xu, Porras, Takemoto, Khalid, Huang. Reviewed submitted version of manuscript: Ahn, Yang, Xu. Approved the final version of the manuscript on behalf of all authors: Ahn. Statistical analysis: Yang. Administrative/ technical/material support: Ahn, Garzon-Muvdi, Caplan, Colby, Coon, Tamargo, Huang. Study supervision: Ahn, Garzon-Muvdi, Caplan, Colby, Coon, Tamargo, Huang.

\section{Supplemental Information \\ Previous Presentations}

The abstract portion of this paper was presented in the form of an oral presentation at the pediatrics section at the 2016 CNS Annual Meeting, September 24-28, 2016, San Diego, California.

\section{Correspondence}

Edward S. Ahn, Department of Neurosurgery, Johns Hopkins Hospital, 600 N Wolfe St., Phipps Ste. 560, Baltimore, MD 21287. email: eahn4@jhmi.edu. 